\title{
Optimal size and length of the endotracheal tube for tracheal intubation via supraglottic airway devices
}

\author{
Fu S. Xue, MD · Jun Xiong, MD • Yu J. Yuan, MD • \\ Qiang Wang, MD
}

Received: 21 February 2010/Accepted: 5 March 2010/Published online: 26 March 2010

(C) Canadian Anesthesiologists' Society 2010

\section{To the Editor,}

We read with interest and some concern the recent correspondence by Takenaka and Aoyama ${ }^{1}$ regarding the optimizing endotracheal tube (ETT) size and length for tracheal intubation through single-use supraglottic airway devices (SADs). We believe the recommendations in this letter to the editor should be interpreted cautiously for the following reasons. First, in Table 1, the authors listed sizes 6.0 and 7.0 RAE ${ }^{\mathrm{TM}}$ nasal ETTs (Mallinckrodt Medical, Athlone, Ireland). Although these ETTs are longer than the standard ETTs, they are used rarely in clinical practice for tracheal intubation through a SAD, because the distal acute curve can impede smooth insertion of the ETT through the $\mathrm{SAD}$, and it can be difficult to remove the SAD along the ETT after successful intubation. In addition, $\mathrm{RAE}^{\mathrm{TM}}$ nasal ETTs are generally not suitable for orotracheal intubation. Second, the authors only assessed the optimal length of ETT required for adequate endotracheal insertion through a $\mathrm{SAD}$. In fact, the greatest challenge encountered when intubating the trachea through a SAD is removing the SAD after successful intubation without dislodging the ETT. ${ }^{2}$ Since the appropriate length of an ETT is only somewhat longer than the sum of the length of a SAD airway tube and $10-11 \mathrm{~cm}$, the proximal end of the ETT is about $3-7 \mathrm{~cm}$ above the proximal end of the airway tube when it has been inserted properly into the trachea through the SAD. With a narrow airway tube of 19-22 cm long, this can make it difficult to remove the SAD safely without dislodging the

F. S. Xue, MD (ه) · J. Xiong, MD · Y. J. Yuan, MD .

Q. Wang, MD

Plastic Surgery Hospital, Chinese Academy of Medical Sciences and Peking Union Medical College, Beijing, China

e-mail: fruitxue@yahoo.com.cn
ETT. Third, other than its total length, another important factor of an ETT that can affect its smooth passage through the SAD is its outer diameter (OD). Although the internal diameter (ID) of the ETT is specified, the OD may vary between different manufacturers because of differences in wall thickness. ${ }^{3}$ Moreover, because of the differences in design features (shape, ID, length of airway tube, and aperture bars) and manufacturers' materials, the capacity to admit passage of the ETT varies among SADs. ${ }^{4,5}$ Therefore, the recommendations herein may be suitable only for the conditions tested by the authors.

Other than the intubating laryngeal mask airway, there are indeed important limitations of tracheal intubation through the SADs. ${ }^{5}$ In view of these problems, we often prefer to perform tracheal intubation through the SAD using an Aintree intubation catheter (AIC) (Cook UK, Letchworth, Herts, UK) loaded onto a fiberoptic bronchoscope (FOB), as described in a previous study. ${ }^{6}$ The AIC was designed specifically to aid fiberoptic intubation through a SAD. The device has an ID that allows it to be mounted onto a $4.0 \mathrm{~mm}$ FOB. At $57 \mathrm{~cm}$ in length, the distal $3 \mathrm{~cm}$ of the FOB remains exposed for unhindered manipulation. After the AIC is placed in the trachea and the FOB is withdrawn, the ETT is railroaded over the AIC into the trachea. This technique can avoid problems relating to incompatibility of the ETT with the SADs during intubation, because the $6.5 \mathrm{~mm}$ OD of the AIC allows railroading of an ETT with an ID $\geq 7.0 \mathrm{~mm}$. Also, this device is likely to reduce the chance of the AIC being hindered at the cross aperture bars of the SAD, as it fits snugly over the FOB. In addition, railroading the ETT over the AIC is likely to be easier than using a FOB alone because of the greater OD of the AIC and the consequent reduction of the gap between the AIC and the ETT. ${ }^{6}$ Some authors recommend this as a "low skill technique". 7 However, this technique does not 
allow direct placement of an ETT through the SAD and is likely to be time consuming.

Competing interests None declared.

\section{References}

1. Takenaka I, Aoyama K. Optimizing endotracheal tube size and length for tracheal intubation through single-use supraglottic airway devices. Can J Anesth 2010; 57: 389-90.

2. Xue FS, Luo MP, Liao X, Tang GZ. Measures to facilitate the classic laryngeal mask airway guided fiberoptic intubation in children with a difficult airway. Paediatr Anaesth 2008; 18: 1273-5.

3. Weiss $M$, Dullenkopf A, Gysin C, Dillier CM, Gerber AC. Shortcomings of cuffed paediatric tracheal tubes. Br J Anaesth 2004; 92: 78-88.

4. Cain JM, Mason LJ, Martin RD. Airway management in two of newborns with Pierre Robin Sequence: the use of disposable vs multiple use LMA for fiberoptic intubation. Paediatr Anaesth 2006; 16: 1274-6.

5. de Lloyd L, Hodzovic I, Voisey S, Wilkes AR, Latto IP. Comparison of fibrescope guided intubation via the classic laryngeal mask airway and i-gel in a manikin. Anaesthesia 2010; 65: 36-43.

6. Blair EJ, Mihai R, Cook TM. Tracheal intubation via the Classic ${ }^{\mathrm{TM}}$ and Proseal ${ }^{\mathrm{TM}}$ laryngeal mask airways: a manikin study using the Aintree intubating catheter. Anaesthesia 2007; 62: 385-7.

7. Higgs A, Clark E, Premraj K. Low-skill fibreoptic intubation: use of the Aintree catheter with the classic LMA. Anaesthesia 2005; 60: $915-20$.

\section{Reply}

We thank Dr. Xue et al. for their interest in our recent letter to the editor. ${ }^{1}$ It should be noted that tracheal intubation through supraglottic airway devices (SADs) is often performed in patients with a difficult airway. This is a lifesaving intubation technique, and it cannot be helped that there are several limitations regarding usable endotracheal tubes (ETTs). Alfery ${ }^{2}$ has suggested the use of the $\mathrm{RAE}^{\mathrm{TM}}$ nasal ETT (Mallinckrodt Medical, Athlone, Ireland) for tracheal intubation through the SADs, and Benumof $^{3}$ has recognized that the preformed curve of the $\mathrm{RAE}^{\mathrm{TM}}$ tube does not present a problem. In addition, we have used the $\mathrm{RAE}^{\mathrm{TM}}$ tube for tracheal intubation through the SADs without difficulty. ${ }^{4}$ Thus, we think that the distal acute curve of the $\mathrm{RAE}^{\mathrm{TM}}$ tube is of minor importance.
In many cases, there is no inherent reason to remove the SADs after successful intubation, except for the intubating laryngeal mask airway. ${ }^{5}$ Leaving the SADs in place is often advantageous in case of a difficult airway. ${ }^{5}$ Thus, we do not consider the method of removing the SADs as being important. Also, when removal was needed, we removed the SADs using $25 \mathrm{~cm}$ long forceps without dislodging the ETT.

We agree completely that the internal diameter and the length of the ETT are not the only important factors, as the outer diameter also affects smooth passage of the ETT through the SADs. The outer diameter of longer ETTs was shown in Table 1 of our recent letter. ${ }^{1}$ In addition to analyzing these longer tubes, we examined passage of representative standard polyvinyl chloride ETTs (Mallinckrodt Medical, Smiths Medical, Parker Medical), and they were passed easily through the SADs that we assessed. However, attention should be paid to the outer diameter when using an ETT of different quality material, e.g., silicone. It is important to ascertain the compatibility between the commonly used SAD and ETT before using them in emergent settings for tracheal intubation.

Conflicts of interest None declared.

\section{References}

1. Takenaka I, Aoyama K. Optimizing endotracheal tube size and length for tracheal intubation through single-use supraglottic airway devices. Can J Anesth 2010; 57: 389-90.

2. Alfery $D D$. Laryngeal mask airway and the ASA difficult airway algorithm: I (Letter). Anesthesiology 1996; 85: 685.

3. Benumof JL. Laryngeal mask airway and the ASA difficult airway algorithm (Letter reply). Anesthesiology 1996; 85: 687-8.

4. Aoyama K, Yasunaga E, Takenaka I, Kadoya T, Sata T, Shigematsu A. Positive pressure ventilation during fibreoptic intubation: comparison of the laryngeal mask airway, intubating laryngeal mask and endoscopy mask techniques. Br J Anaesth 2002; 88: 246-54.

5. Benumof $J L$. Laryngeal mask airway and the ASA difficult airway algorithm. Anesthesiology 1996; 84: 686-99.

Ichiro Takenaka, MD

Kazuyosi Aoyama, MD

Nippon Steel Yawata Memorial Hospital, Yahatahigashi-ku,

Kitakyushu, Japan 